\title{
Study of Third-Order Nonlinear Optical Properties of Basic Violet 3 Dye in Polar Protic and Aprotic Solvents
}

jeyaram s ( $\sim$ jeyaram.msc@gmail.com )

surya group of institutions https://orcid.org/0000-0002-1332-4237

\section{Research Article}

Keywords: Basic violet 3 dye, TONLO, polar protic and aprotic solvents, saturable and reverse saturable absorption

Posted Date: June 9th, 2021

DOI: https://doi.org/10.21203/rs.3.rs-573986/v1

License: (ㅇ (i) This work is licensed under a Creative Commons Attribution 4.0 International License. Read Full License

Version of Record: A version of this preprint was published at Journal of Fluorescence on August 9th, 2021. See the published version at https://doi.org/10.1007/s10895-021-02796-z. 


\title{
Study of third-order nonlinear optical properties of basic violet 3 dye in polar protic and aprotic solvents
}

\author{
S Jeyaram \\ Department of Physics, School of Engineering and Technology, Surya Group of Institutions, Vikravandi, \\ Villupuram-605652, Tamilnadu, India.
}

Email

jeyaram.msc@gmail.com

\begin{abstract}
The present work aims to study of third-order nonlinear optical (TONLO) behavior of basic violet 3 dye dissolved in polar protic and aprotic solvents, namely, ethanol, 1-propanol, acet0one and dimethyl sulfonate (DMSO), respectively. The polarity of the solvent used to have a substantial impact on the linear and TONLO properties of the dye sample. The dye exhibit self-defocusing nonlinearity due to thermally induced nonlinear refractive index and nonlinear absorption coefficient reveals the character of both saturable and reverse saturable absorption (RSA). The order of magnitude of nonlinear refractive index $\left(\mathrm{n}_{2}\right)$ and nonlinear coefficient of absorption $(\beta)$ of dye sample was determined to be $10^{-7} \mathrm{~cm}^{2} / \mathrm{W}$ and $10^{-3} \mathrm{~cm} / \mathrm{W}$, respectively. The real and imaginary factors of the TONLO susceptibility of basic violet 3 dye were measured to be the power of $10^{-5}$ esu. The results are revealed that the possibility of utilizing the dye sample in various photonics and optoelectronics applications.
\end{abstract}

Keywords: Basic violet 3 dye: TONLO: polar protic and aprotic solvents: saturable and reverse saturable absorption. 


\section{Introduction}

Nonlinear optics is an exciting filed of physics that plays a major role in modern telecommunication technology [1]. Nonlinear optics has grown after the discovery of second harmonic generation by Franken and his co-workers [2]. An intense light beam can modify the physical and chemical properties of materials which lead to applications in photonics and optoelectronics [3]. Nonlinear optical (NLO) materials have been widely used in two-photon microscopy, optical switching, data storage, optical communication, and eye and sensor production [4-6]. The uses of photonic materials in optical switching and computing have been the advantage to increase the speed of an information process. The materials used for NLO study are not limited, and covers a wide range such as organic [7], inorganic [8], semiconductor [9], metal nanoparticles [10], natural pigments [11, 12], etc. The interest for studying NLO properties of organic materials has gained in popularity due to their merit of large nonlinearity and hyperpolarizability, good photo-thermal stability, quick response time, modification of chemical structure, high damage threshold, ease of processing, etc [13]. Organic dyes are one among them; exhibit a large TONLO susceptibility due to $\pi$-conjugated electrons with donor-acceptor configuration [14-17]. Basic violet 3 is a triarylmethane dye and seems to have a bright blue purple color. This dye can be produced by condensation of 4dimethylaminobenzaldehyde with dimethylaniline, followed by oxidation of the leuco base. Basic violet 3 dye is one of the oldest types of synthetic dye which is widely used as a biological stain in veterinary medicine, papermaking, leather, food, cosmetic industries, textile, and printing [18].

Molecular surrounding environment has had an influence on the physical and chemical behavior of organic materials [19]. The interaction between solute and solvent is divided into specific (hydrogen bonding) and non-specific (dielectric enhancement) interactions and the effect of solvent on solute molecules can be determined by using solvatochromism and solvent polarity index [20]. Polar solvents have a large dipole moment and are classified as polar protic and aprotic solvents. Polar protic solvents are hydrogen bond donating, which possess O-H or N-H bonds. Polar aprotic solvents are hydrogen bond accepting, because they do not have $\mathrm{O}-\mathrm{H}$ or N-H bonds. Among the various experimental methods, Z-scan technique [21] is a single beam technique that concurrently evaluates the real and imaginary components of the TONLO susceptibility, as well as the sign and magnitude of nonlinear 
index of refraction and nonlinear coefficient of absorption of the sample can be obtained from simple experimental calculations. During beam propagation, the phase distortion transferred to amplitude distortion is the principle of Z-scan technique. TONLO susceptibility $\left(\chi^{(3)}\right)$ of basic violet 3 dye in protic and aprotic solvents is determined from real and imaginary factors of the TONLO susceptibility. The real part of TONLO susceptibility is directly proportional to nonlinear refractive index, while the imaginary part of TONLO susceptibility is directly related to nonlinear coefficient of absorption. Therefore, $\mathrm{n}_{2}$ and $\beta$ are the essential parameters to calculate the TONLO susceptibility, which is determined from closed and open aperture Z-scan technique. A circular aperture is employed in closed aperture technique and placed at far-field with a linear aperture transmittance of $S=0.40$. The aperture was replaced with a convex lens to gather the total transmittance of the sample is known as open aperture $(S=1)$ technique. This paper reports the TONLO characteristics of basic violet 3 dye dissolved in protic and aprotic solvents using a continuous wave laser working at $635 \mathrm{~nm}$ wavelength.

\section{Experimental}

\section{Materials}

Sigma Aldrich provided the basic violet 3 dye (C.I: 42555) and the solvents utilized in the present study. Fig. 1 depicts the chemical structure of basic violet 3 dye. The UV-Visible absorption spectrum of basic violet 3 dye in polar protic and aprotic solvents is shown in Fig. 2 (concentration: $10^{-5} \mathrm{M}$ ). The linear absorption coefficient of basic violet 3 dye is highly dependent on solvent polarity and exhibit a large linear absorption coefficient at high polarity solvents (DMSO). A low polarizability of polar solvent shows a minimum value of linear absorption coefficient (1-propanol), which exhibits a considerable nonlinear refractive index. Furthermore, the maximum absorption peak of the dye sample in polar protic and aprotic solvents was observed towards the red region with the increase of solvent polarity, suggesting a positive solvatochromism. When the solute is dissolved in various solvents, the size of electronic ground and excited states of the solute are changes is described as positive solvatochromism which corresponds to bathochromic shift or red shift of the sample [22]. The spectral parameters and linear absorption coefficient of basic violet 3 dye in polar protic and aprotic solvents are tabulated in Table 1. 


\section{Methods}

Fig. 3 depicts the closed and open aperture experimental setup employed in this study. A single beam Z-scan technique consists of a solid state diode laser operating at $635 \mathrm{~nm}$ wavelength with $5 \mathrm{~mW}$ power. The beam was focused by a convex lens with focal length of 5 $\mathrm{cm}$. The sample is moved between $-\mathrm{Z}$ and $+\mathrm{Z}$ positions using a micrometer translational stage. The transmittance of the sample was measured by a power meter at far-field. The thin sample approximation was validated in the present study, because the measured Rayleigh length is greater than sample length.

\section{Results and discussion}

When a high-intensity laser beam interacts with the material, the phase and amplitude of the beam was affected. The intensity-dependent nonlinear index of refraction index and nonlinear coefficient of absorption are defined as [14],

$n=n_{0}+n_{2} I$

$\alpha=\alpha_{0}+\beta I$

where $\mathrm{n}, \mathrm{n}_{0}, \mathrm{n}_{2}, \alpha, \alpha_{0}, \beta$ and $\mathrm{I}$ are refers to refractive index, linear refractive index, nonlinear refractive index, absorption coefficient, linear absorption coefficient, nonlinear absorption coefficient and intensity of the light, respectively.

Fig. 4 (a-d) illustrates the nonlinear absorption coefficient of basic violet 3 dye in polar protic and aprotic solvents and exhibits the signature of both saturable and reverse saturable absorption (RSA). In ethanol solution, the basic violet 3 dye tend to RSA due to low polarity, while other solvents, such as 1-propanol, DMSO and acetone, the sample shows saturable absorption (SA) owing to high polarity [23]. Either SA or RSA is the characteristics property of materials induced by increases or decreases of transmittance of light at the focal point $(\mathrm{Z}=0$ ). From Fig. 4 (b-d), the transmittance of basic violet 3 dye in 1-propanol, DMSO and acetone are increases at the focal point are the signature of SA and hence the normalized transmittance trace shows a peak at the focus. Furthermore, the open aperture transmittance traces exhibit a symmetric structure with respect to the focal point, indicating an intensity dependent absorption effect. SA arises at high input intensities and causes a significant increase in photon absorption before relaxing to the ground state [19]. The absorption cross section of ground state is greater than that of the excited state indicates the existence of SA in 
dye molecule. On the other hand, Fig 4 (a) shows the RSA behavior of basic violet 3 dye in ethanol, where the excited state absorption cross-section is greater than ground state absorption cross-section. The RSA behavior of basic violet 3 dye is explained using a fivelevel model which is same as that of our previously published work [14]. The model comprises of singlet and triplet states with different energy states such as $S_{0}, S_{1}, S_{2}, T_{1}$ and $T_{2}$ respectively. Transition between singlet ground state $\left(S_{0}\right)$ and excited singlet state $\left(S_{2}\right)$ by absorption of two photons is known as two-photon absorption. Transition between first singlet state $\left(\mathrm{S}_{1}\right)$ and first triplet state $\left(\mathrm{T}_{1}\right)$ via intersystem crossing is described as saturable absorption. Transition from first singlet state $\left(S_{1}\right)$ to excited singlet state $\left(S_{2}\right)$ or first triplet state $\left(\mathrm{T}_{1}\right)$ to excited triplet state $\left(\mathrm{T}_{2}\right)$ is known as excited-state absorption (ESA) or reverse saturable absorption (RSA). RSA is the most important nonlinear absorption process in organic dyes, and it might be improved if electrons from $S_{1}$ were moved to $T_{1}$ via an intersystem crossing from where $\mathrm{T}_{2}$ would occur. Due to continuous absorption of laser irradiation at a wavelength of $635 \mathrm{~nm}$, the ESA also contribute to the absorption process [14]. Therefore, the observed nonlinear absorption of basic violet 3 dye in ethanol solution is ESA assisted RSA.

The normalized transmittance from open aperture $\mathrm{Z}$-scan method using the fitting curve is given by

$$
\begin{aligned}
& T(z, s=1)=\sum_{m=0}^{\infty} \frac{\left[-q_{o}(z)\right]^{m}}{(m+1)^{3 / 2}} q_{o}(0)<1 \\
& q_{0}(z)=\frac{\beta I_{o} L_{e f f}}{\left(1+Z^{2} / Z_{0}^{2}\right)}
\end{aligned}
$$

where $\mathrm{Z}_{\mathrm{o}}$ and $\mathrm{L}_{\text {eff }}$ and are the diffraction and effective length of the sample.

The nonlinear refractive index of basic violet 3 dye in protic and aprotic solvents is determined from closed aperture Z-scan technique. The nonlinear refraction in closed aperture method includes the parameters of nonlinear coefficient of absorption. As a result, separating the closed aperture data from open aperture data yields the samples pure nonlinear refraction data. The pure nonlinear refraction curve of basic violet 3 dye in polar protic and aprotic solvents is shown in Fig. 5 (a-d). The normalized transmittance trace shows a peak followed by a valley is the character of self-defocusing or negative nonlinear refractive index. The self-defocusing effect is the result of thermal nonlinearity which arises from continuous absorption of laser radiation at $635 \mathrm{~nm}$ wavelength. The heat is generated inside the sample 
by light absorption, which causes a change in refractive index. The peak-valley difference is higher than 1.7 times $\mathrm{Z}_{\mathrm{R}}$ is the confirmation of thermal nonlinearity and obtained the result is a cubic nonlinearity [14].The normalized transmittance of basic violet 3 dye is determined from the closed aperture Z-scan data using the relation,

$T(z)=1-\Delta \emptyset_{o} \frac{4 X}{\left(X^{2}+1\right)\left(X^{2}+9\right)}$

where $\mathrm{X}=\mathrm{Z} / \mathrm{Z}_{0}$. The nonlinear refractive index can be determined using the relation is given by

$n_{2}=\frac{\Delta \emptyset_{0} \lambda}{2 \pi I_{0} L_{e f f}}\left(\frac{\mathrm{cm}^{2}}{W}\right)$

where $\Delta \emptyset_{0}, \lambda$ and $I_{0}$ be the on-axis phase shift, wavelength and intensity of the input beam. The on-axis phase shift related to peak-valley difference is given by,

$\Delta \emptyset_{0}=\frac{\Delta T_{p-v}}{0.406(1-S)^{0.25}}$

where $\mathrm{S}$ is the linear aperture transmittance.

The nonlinear refractive index $\left(\mathrm{n}_{2}\right)$ of basic violet 3 dye in polar protic and aprotic solvents is tabulated in Table 2. From the table, it is clear that the $\mathrm{n}_{2}$ of basic violet 3 dye in 1-propanol has higher than that of other solvents. The real and imaginary components of TONLO susceptibility of basic violet 3 dye in polar protic and aprotic solvents is given by,

$\operatorname{Re}\left[\chi^{(3)}\right](e s u)=\frac{\varepsilon_{0} c^{2} n_{0}^{2}}{10^{4} \pi} n_{2}\left(\frac{c m^{2}}{W}\right)$

$\operatorname{Im}\left[\chi^{(3)}\right](e s u)=\frac{\varepsilon_{0} c^{2} n_{0}^{2} \lambda}{10^{2} 4 \pi^{2}} \beta\left(\frac{c m}{W}\right)$

where $\varepsilon_{0}$ is the permittivity of free space and $\mathrm{c}$ is the velocity of light in vacuum. The $\chi^{(3)}$ of basic violet 3 dye was calculated by using the relation,

$\chi^{(3)}=\sqrt{\left(\operatorname{Re}\left(\chi^{3}\right)^{2}+\left(\operatorname{Im}\left(\chi^{3}\right)^{2}\right.\right.}(e s u)$

The TONLO parameters of basic violet 3 dye in polar protic and aprotic solvents are tabulated in Table 2. From Table 2, the TONLO susceptibility $\left(\chi^{3}\right)$ of basic violet 3 in 1propanol has higher than that of other solvents. The value of TONLO susceptibility of basic 
violet 3 dye in the present study was compared with some reported materials [24-27] and it is worth noting that, the obtained results are higher than that of reported materials.

TONLO behavior of basic violet 3 dye is highly depends on the solvent polarity parameter. The solvent polarity parameters and several intermolecular interactions are induced and lead to significant effects in the solute molecules. The nonlinear absorption transmittance curve in Fig. 4 (a-d) shows a switchover from RSA to SA is due to increase of polarizability of polar solvents. Therefore, increasing the solvent polarity/polarizability, basic violet 3 dye tend to saturable absorption. Also, the solvent hydrogen bond donor and acceptor play a significant role in the present study. By increasing the solvent hydrogen bond donor, the solute molecules tend to RSA. Furthermore, a large value of solvent hydrogen bond acceptor exhibits a large TONLO susceptibility (1-propanol > ethanol > DMSO>acetone). The observed results are in good agreement with previously published work [23].

\section{Conclusion}

TONLO behavior of basic violet 3 dye in polar protic and aprotic solvents was examined by a $5 \mathrm{mw}$ power $\mathrm{CW}$ laser working at $635 \mathrm{~nm}$ wavelength. The linear and TONLO properties of dye sample were greatly dependent on solvent polarity and exhibit large third-order susceptibility when it is dissolved in polar protic solvent. The closed aperture Z-scan traces of basic violet 3 dye in polar protic and aprotic solvents exhibits self-defocusing nonlinearity, while the open aperture Z-scan traces displays the behavior of both saturable and reverse saturable absorption. TONLO susceptibility $\left(\chi^{3}\right)$ of basic violet 3 dye was measured to be the order of $10^{-5}$ esu and exhibit a large nonlinear optical susceptibility by dissolving the dye sample with polar protic solvents such as 1-propanol and ethanol. The results are suggested that, the dye sample studied here is a potential candidate for applications in photonics and optoelectronics. 


\section{$\underline{\text { Author Declarations }}$}

\section{Funding Information:}

No financial support for the research

\section{Conflict of Interest}

The author declare that there is no conflict of interest

\section{Ethics approval/declaration}

Not applicable

\section{Consent to participate}

Not applicable

\section{Consent for participate}

Not applicable

\section{$\underline{\text { Availability of data and materials/Data availability }}$}

The datasets generated during the current study is available from the corresponding author

\section{Code availability}

The software process in the current study is available from the corresponding author

\section{Author Contribution}

$\begin{array}{lr}\text { Conceptualization } & : \text { S Jeyaram } \\ \text { Methodology } & : \text { S Jeyaram } \\ \text { Validation } & \text { S Jeyaram } \\ \text { Writing-Review \& Editing: S Jeyaram } \\ \text { Supervision }\end{array}$




\section{References}

1. Robert W. Boyd (2007) Nonlinear optics, Academic Press, Third edition.

2. Franken PA, Hill AE, Peters CW, Weinreich G (1961) Generation of optical harmonics. J. Phys. Rev. Lett. 7: 118.

3. Shen YR (1984) Principle of nonlinear optics, John Wiley, First edition, New York.

4. Sreenath MC, Hubert Joe I, Rastogi VK (2018) Third-order optical nonlinearities of 1,-diaminoanthraquinone for optical limiting applications. Opt. Laser Technol. 108: 218-234. https://doi.org/10.1016/j.optlastec.2018.06.056.

5. Jeyaram S, Geethakrishnan $\mathrm{T}$ (2020) Spectral and third-order nonlinear optical characteristics of natural pigments extracted from coriandrum sativum. Opt. Mater.107: 110148. https://doi.org/10.1016/j.optmat.2020.110148.

6. Kramer MA, Tompkin WR, Boyd RW (1986) Nonlinear optical interactions in fluorescein-doped boric acid glass. Phys. Rev. A 34: 2026-2031. https://doi.org/10.1103physreva.34.2026.

7. He GS, Xu GS, Prasad PN, Reinhardt BA, Bhatt JC, Dillard AG (1995) Two-photon absorption and optical limiting properties of novel organic compounds. Opt. Lett. 20: 435-437. https://doi.org/10.1364/ol.20.000435.

8. Ramki C, Ezhil Vizhi R (2018) Insight on the growth and property studies of inorganic hydrated borate $\left(\mathrm{Na}_{6}\left[\mathrm{~B}_{4} \mathrm{O}_{5}(\mathrm{OH})_{4}\right]_{3} .8 \mathrm{H}_{2} \mathrm{O}\right)$ single crystal- An effective third order nonlinear optical (NLO) material for optical limiting application. Mater. Chem. Phys. 205: 138-146. https://doi.org/10.1016/j.matchemphys.2017.11.014.

9. Saeed A, Razvi MAN, Salah N (2021) Third-order nonlinear optical properties of the small-molecular organic semiconductor tris (8-Hydroxyquinoline) aluminium by $\mathrm{CW}$ $\begin{array}{llll}\text { Z-scan technique. } & \text { Results } & \text { Phys. }\end{array}$ https://doi.org/10.1016/j.rinp.2021.104162.

10. Ryasnyansky AI, Palpant B, Debrus S, Khalibullin RI, Stepanov AL (2006) Nonlinear optical properties of copper nanoparticles synthesized in indium tin oxide matrix by ion implantation. J. Opt. Soc. Am. B 23: 1348-1353. https://doi.org/10.1364/JOSAM.23.001348. 
11. Jeyaram S, Geethakrishnan $\mathrm{T}$ (2019) Linear and nonlinear optical properties of chlorophyll-a extracted from Andrographis paniculata leaves. Opt. Laser Technol. 116: 31-36. https://doi.org/10.1016/j.optlastec.2019.03.013.

12. Zongo S, Sanusi K, Britton J, Mthunzi P, Nyokong T, Maaza M, Sahraoui B (2015) Nonlinear optical properties of natural laccaic dye studied using Z-scan technique. Opt. Mater. 46: 270-275. https://doi.org/10.1016/j.optmat.2015.04.031.

13. Nalwa HS (1993) Organic materials for third-order nonlinear optics. Adv. Mater. 5: 341-358. https://doi.org/10.1002/adma.19930050504.

14. Jeyaram S, Geethakrishnan T (2017) Third-order nonlinear optical properties of acid green 25 dye using Z-scan method. Opt. Laser Technol. 89: 179-185. https://doi.org/10.1016/j.optlastec.2016.10.006.

15. Jeyaram S, Hemalatha S, Geethakrishnan T (2020) Nonlinear refraction, absorption and optical limiting properties of disperse blue 14 dye. Chem. Phys. Lett. 739: 137037. https://doi.org/10.1016/j.cplett.2019.137037.

16. Ghaleh KJ, Salmai S, Ara MHM (2007) Nonlinear responses and optical limiting behavior of fast green FCF dye under a low power CW He-Ne laser irradiation. Opt. Commun. 271: 551-554. https://doi.org/10.1016/j.optcom.2006.10.037.

17. Choubey RK, Medhekar S, Kumar R (2014) Study of nonlinear optical properties of organic dye by Z-scan technique using He-Ne laser. J. Mater. Sci. Mater. Elect. 25: 1410-1415. https://doi.org/10.1007/s10854-014-1743-3.

18. Chen $\mathrm{CH}$, Chang CF, Ho CH (2008) Biodegradation of crystal violet by a shewanella $\begin{array}{llll}\text { sp. NTOU1. } & \text { J. } & \text { Chemosphere } & \text { 1712-1720. }\end{array}$ https://doi.org/10.1016/j.chemosphere.2008.04.069.

19. Jeyaram S, Geethakrishnan T (2020) Solvent dependent linear and nonlinear optical characteristics of acid blue 3 dye. J. Fluores. 30: 1161-1169. https://doi.org/1007/s10895-020-02580-5. 
20. Khadem Sadigh M, Zakerhamidi MS (2018) Media polarity and concentration roles on the third-order nonlinear behaviors of thiazine dyes. Opt. Laser Technol. 100: 216224. https://doi.org/10.1016/j.optlastec.2017.10.007.

21. Sheik-Bahae M, Said AA, Wei T, Hagan DJ, Van Stryland EM (1990) Sensitive measurement of optical nonlinearities using a single beam. IEEE J. Quant. Elect. 26: 760-769. https://doi.org/10.1109/3.53394.

22. Reichardet C (1988) Solvents and Solvent Effects in Organic Chemistry, Second ed., VCH, New York.

23. Khadem Sadigh M, Zakerhamidi MS, Rezaei B, Milachian K (2017) Environment effects on the nonlinear absorption properties of methylene blue under different power of excitation beam. J. Mol. Liq. 229: 548-554. https://doi.org/10.1016/j.molliq.2016.12.108.

24. Jeyaram S (2021) Intermolecular charge transfer in donor-acceptor substituted triarylmethane dye for NLO and optical limiting applications. J. Mater. Sci. Mater. Elect. 32: 9368-9376. https://doi.org/10.1007/s10854-021-05600-7.

25. Shkir M, Khan ZR, Anis M, Shaikh SS, AlFaify S (2020) A comprehensive study of opto-electrical and nonlinear properties of $\mathrm{Cu} @ \mathrm{CdS}$ thin films for optoelectronics. Chin. J. Phys. 63: 51-62. https://doi.org/10.1016/j.cjph.2019.10.017.

26. Shinde SS, Sreenath MC, Chitrambalam S, Jeo IH, Sekar N (2020) Spectroscopic, DFT and Z-scan approach to study linear and nonlinear optical properties of Disperse Red 277. Opt. Mater. 99: 109536. https://doi.org/10.1016/j.optmat.2019.109536.

27. Cheng Y, He T, Hao H, Zhu S, Xiao H (2009) Z-scan study of optical nonlinearities in two fullerene derivatives. Opt. Commun. 282: 4271-4275. https://doi.org/10.1016/j.optcom.2009.07.038. 
Table 1. Linear and spectroscopic parameters of polar protic and aprotic solvents

\begin{tabular}{ccccccc}
\hline Solvent & $\begin{array}{c}\text { Linear } \\
\text { refractive } \\
\text { index } \\
\left(\mathrm{n}_{0}\right)\end{array}$ & $\begin{array}{c}\text { Dielectric } \\
\text { constant } \\
(\varepsilon)\end{array}$ & $\begin{array}{c}\text { Hydrogen } \\
\text { bond donor } \\
(\alpha)\end{array}$ & $\begin{array}{c}\text { Hydrogen } \\
\text { bond } \\
\text { acceptor } \\
(\beta)\end{array}$ & $\begin{array}{c}\text { Polarizability } \\
\left(\pi^{*}\right)\end{array}$ & $\begin{array}{c}\text { Linear absorption } \\
\text { coefficient } \\
\left(\alpha_{0} / \mathrm{cm}\right)\end{array}$ \\
\hline Polar Protic & & & & & \\
Ethanol & 1.361 & 24.5 & 0.86 & 0.75 & 0.52 & 0.430 \\
1-Propanol & 1.385 & 20.60 & 0.78 & 0.83 & 0.54 & 0.195 \\
Polar aprotic & & & & & \\
DMSO & 1.479 & 46.68 & 0.00 & 0.76 & 1.00 & \\
Acetone & 1.359 & 21.01 & 0.08 & 0.48 & 0.633 & \\
\end{tabular}


Table 2. TONLO properties of basic violet 3 dye in polar protic and aprotic solvents

\begin{tabular}{cccccc}
\hline Solvent & $\begin{array}{c}\mathrm{n}_{2} \times 10^{-7} \\
\left(\mathrm{~cm}^{2} / \mathrm{W}\right)\end{array}$ & $\begin{array}{c}\beta \times 10^{-3} \\
(\mathrm{~cm} / \mathrm{W})\end{array}$ & $\begin{array}{c}\mathrm{Re} \chi^{(3)} \times 10^{-5} \\
(\mathrm{esu})\end{array}$ & $\begin{array}{c}\operatorname{Im} \chi^{(3)} \times 10^{-5} \\
(\mathrm{esu})\end{array}$ & $\begin{array}{c}\chi^{(3)} \mathrm{X} \mathrm{10^{-5 }} \\
(\mathrm{esu})\end{array}$ \\
\hline Ethanol & -1.56 & 4.11 & 0.73 & 0.97 & 1.21 \\
1-Propanol & -2.59 & -3.80 & 1.26 & -0.09 & 1.26 \\
DMSO & -2.09 & -3.93 & 1.16 & -0.11 & 1.16 \\
Acetone & -1.59 & -5.55 & 0.75 & -0.13 & 0.77 \\
\hline
\end{tabular}




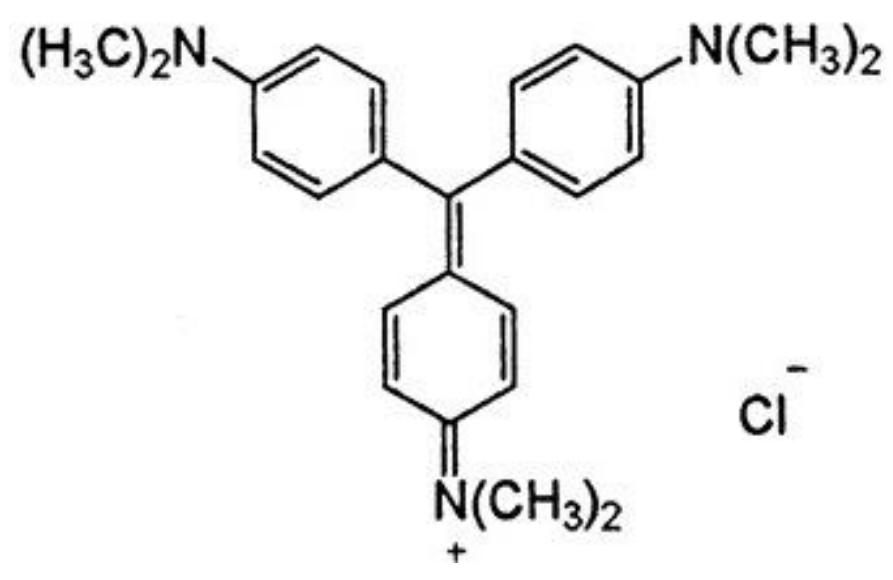

Fig. 1 Molecular structure of basic violet 3 dye 


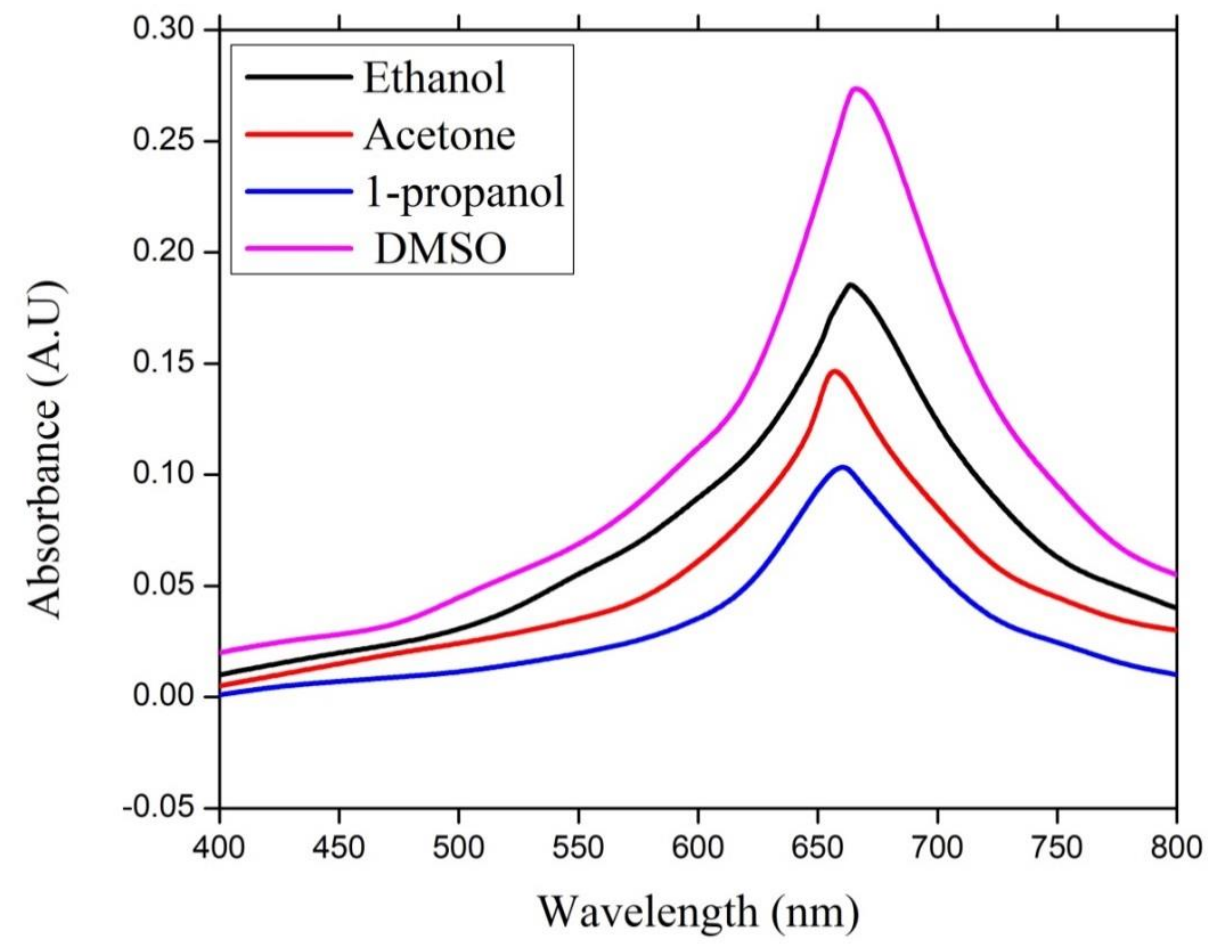

Fig. 2 UV-Visible absorption spectra of basic violet 3 dye in protic and aprotic solvent 

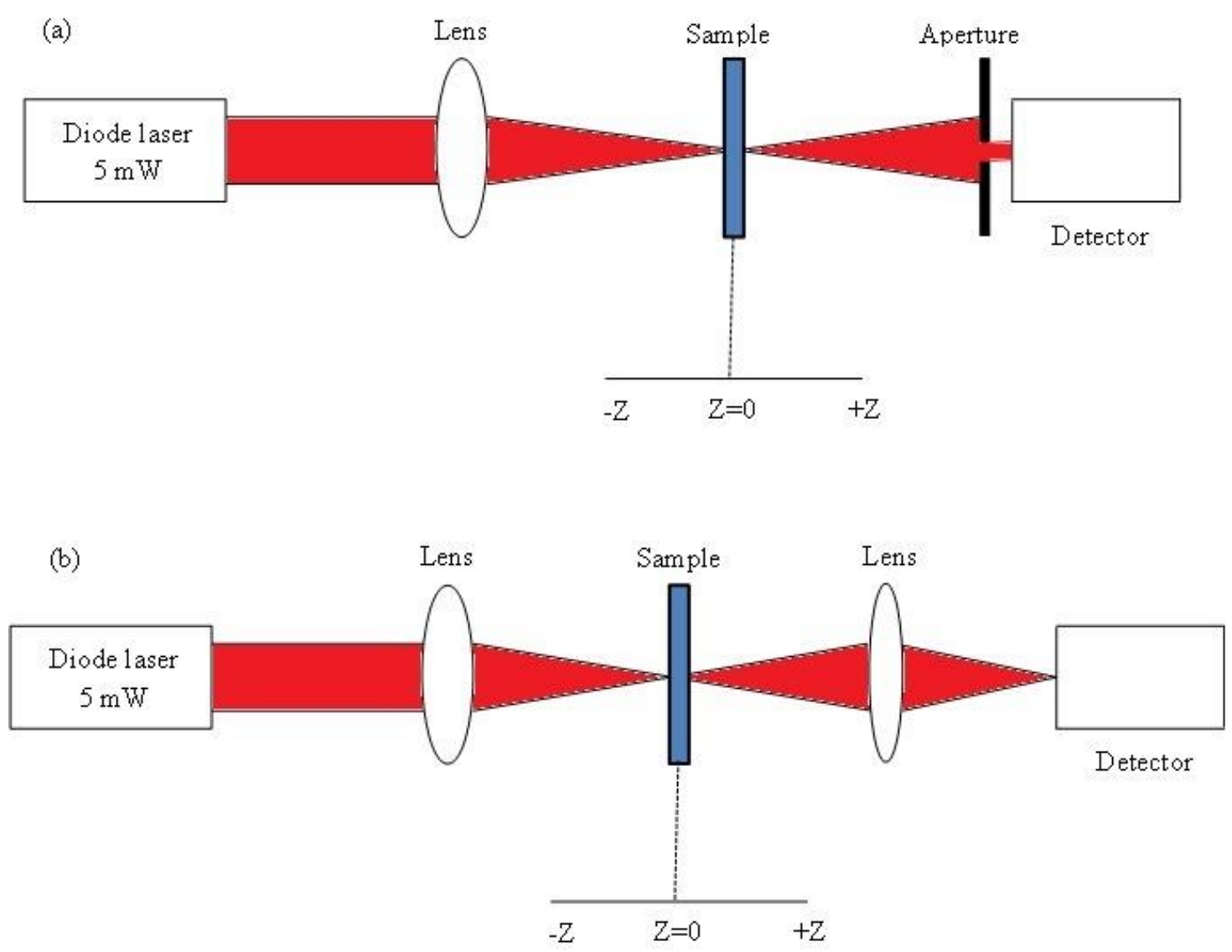

Fig. 3 Schematic of (a) closed and (b) open aperture Z-scan method 

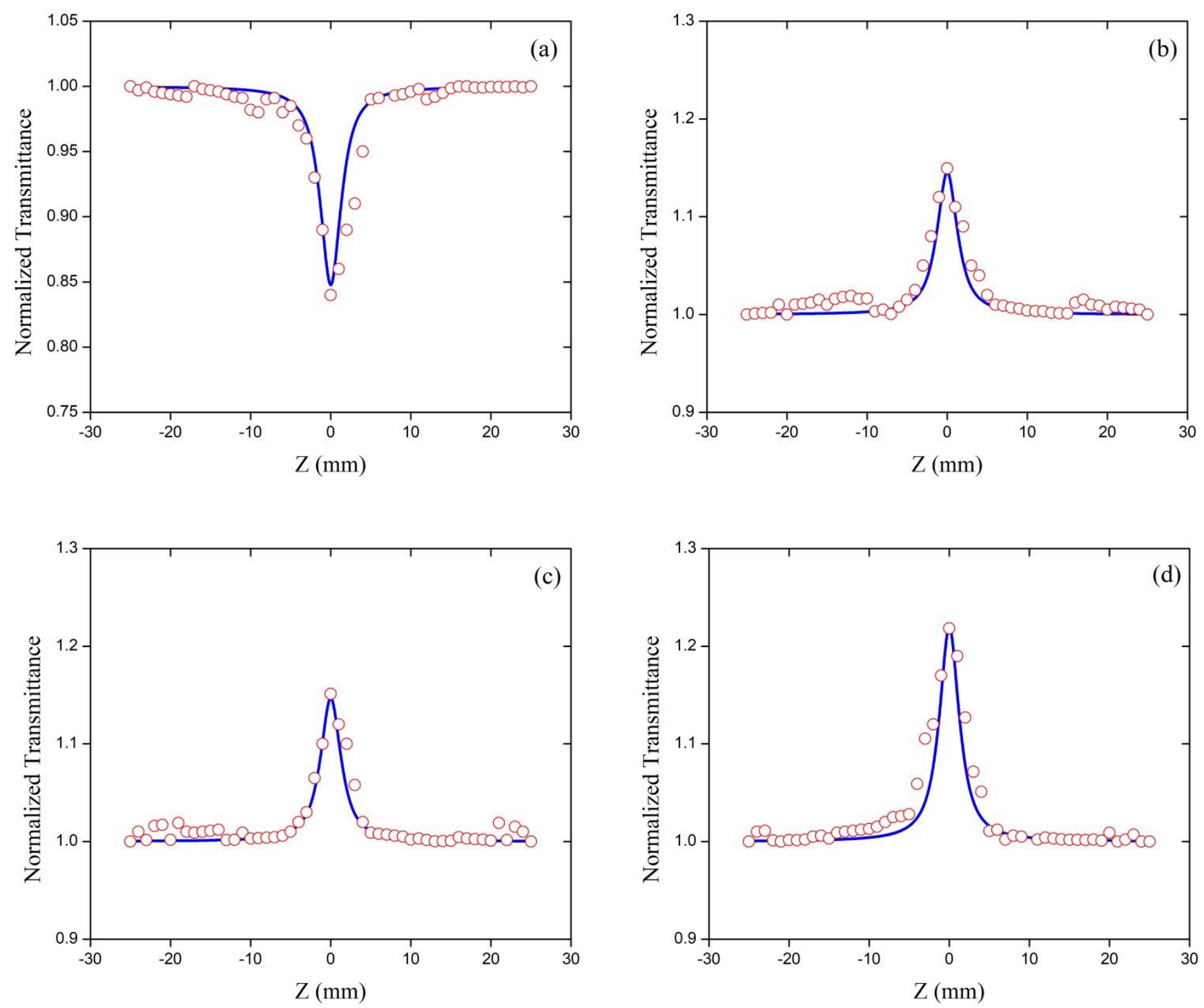

Fig. 4 Open aperture Z-scan curve of basic violet 3 dye dissolved in (a) Ethanol (b) 1-propanal (c) DMSO (d) Acetone. 

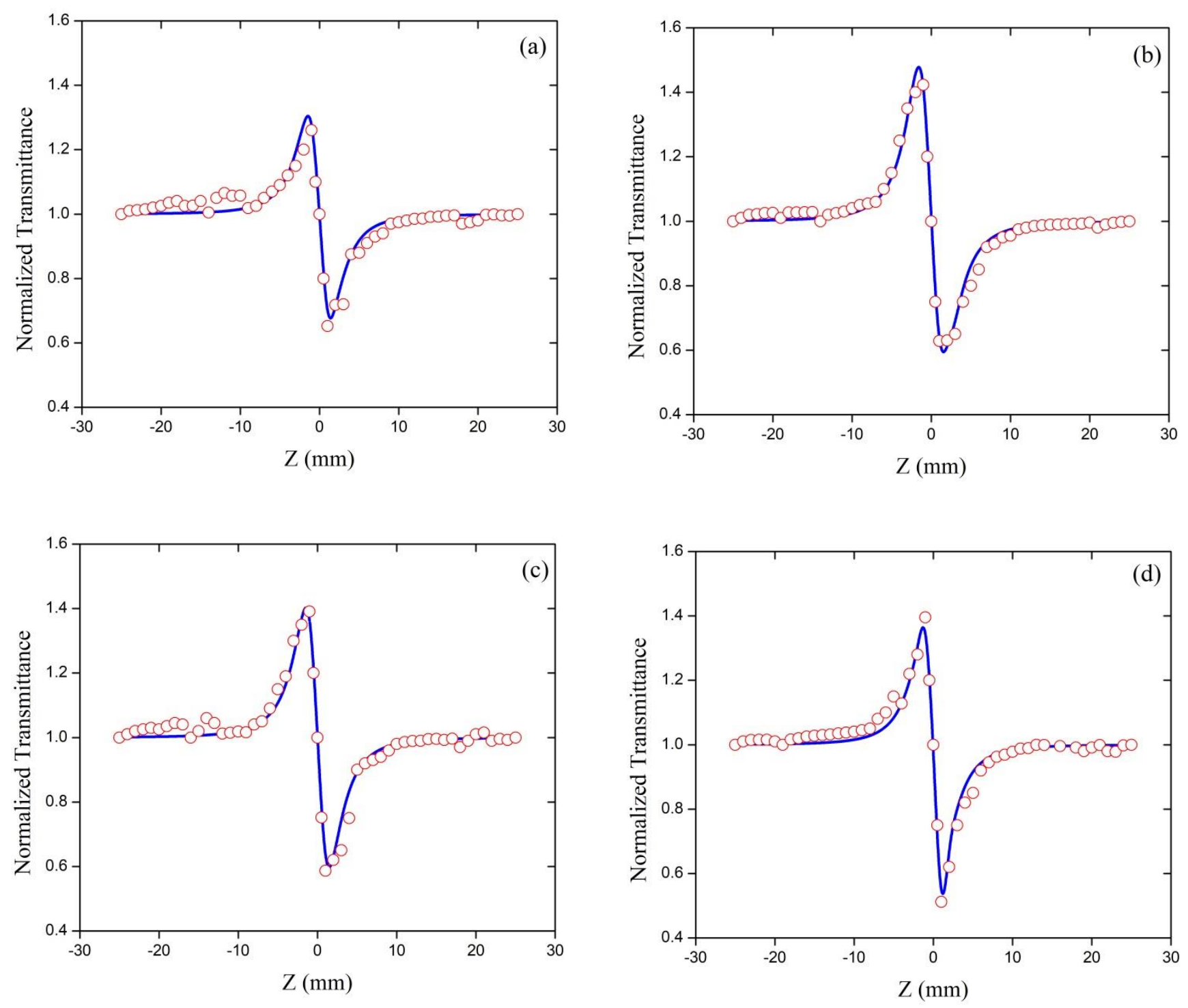

Fig. 5 Closed aperture Z-scan curve of basic violet 3 dye dissolved in (a) Ethanol (b) 1propanal (c) DMSO (d) Acetone. 
Figures

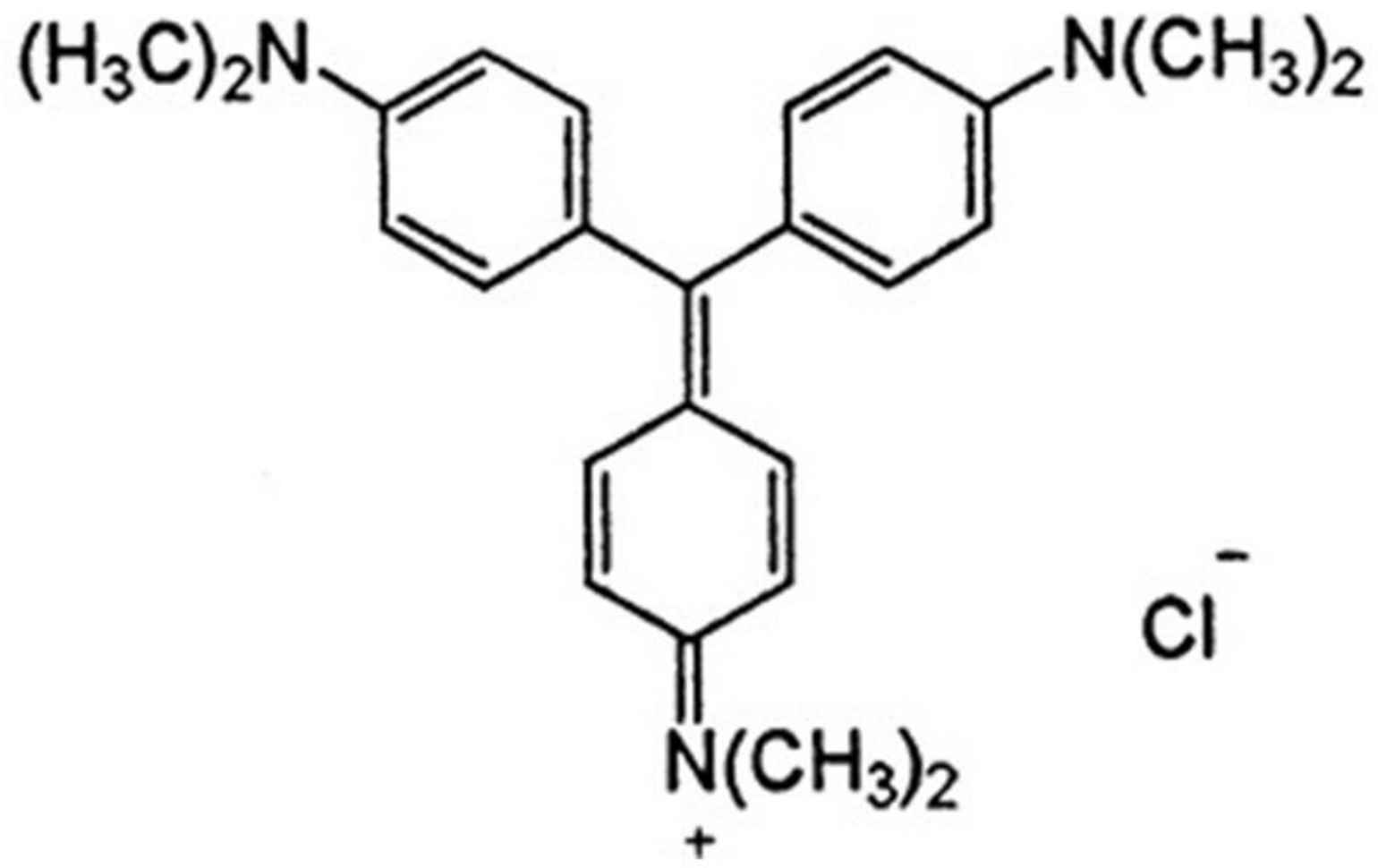

Figure 1

Molecular structure of basic violet 3 dye 


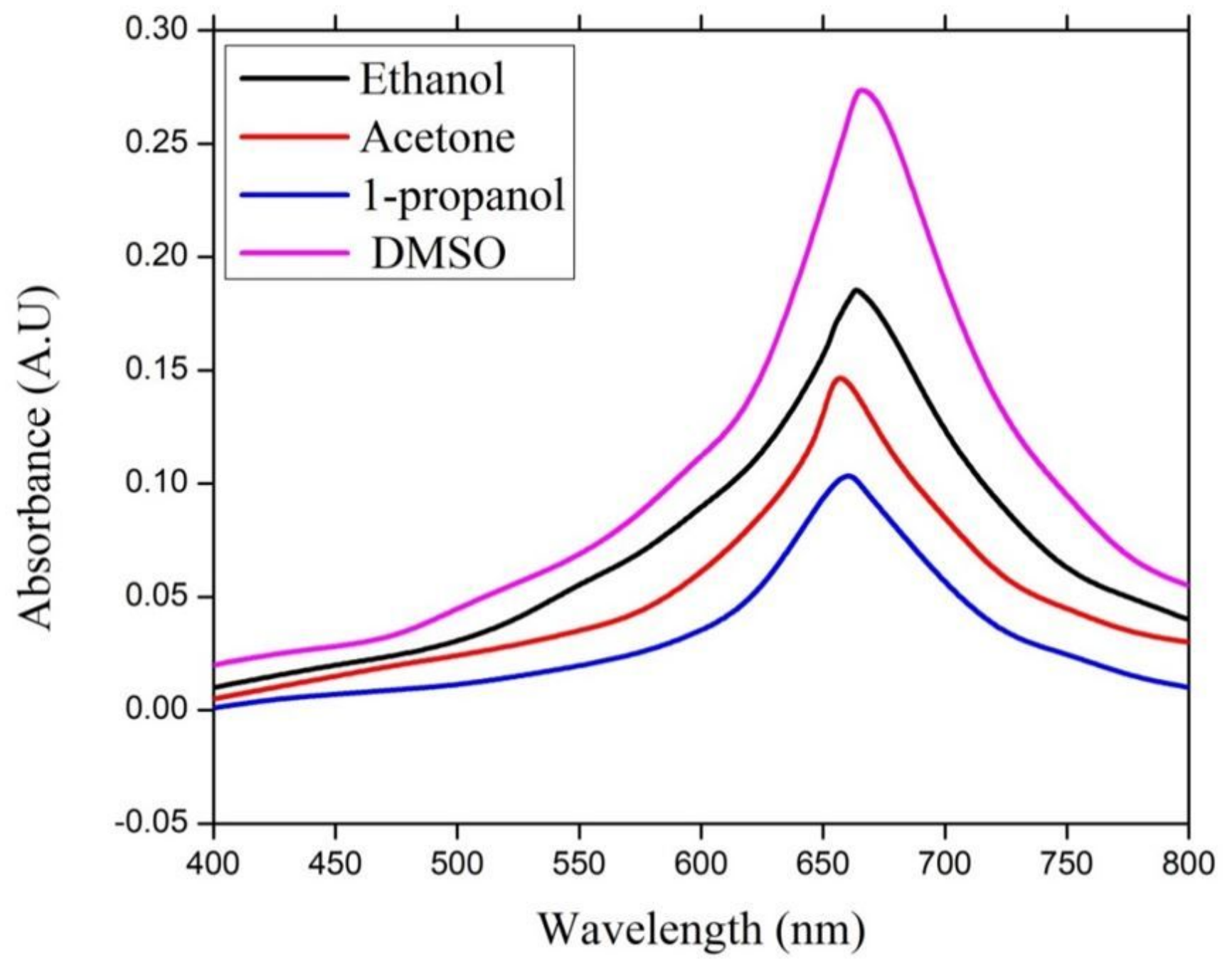

Figure 2

UV-Visible absorption spectra of basic violet 3 dye in protic and aprotic solvent 

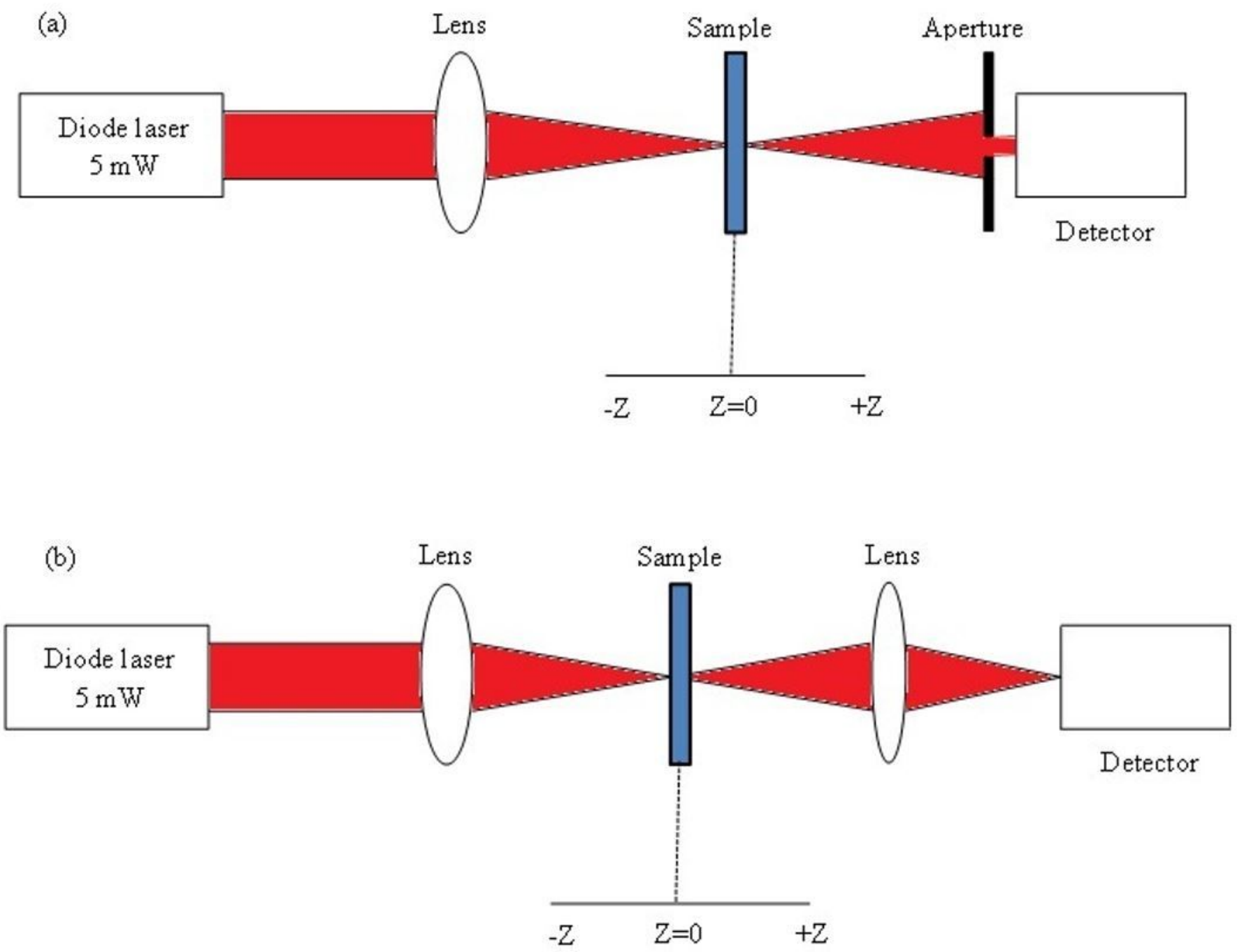

Figure 3

Schematic of (a) closed and (b) open aperture Z-scan method 

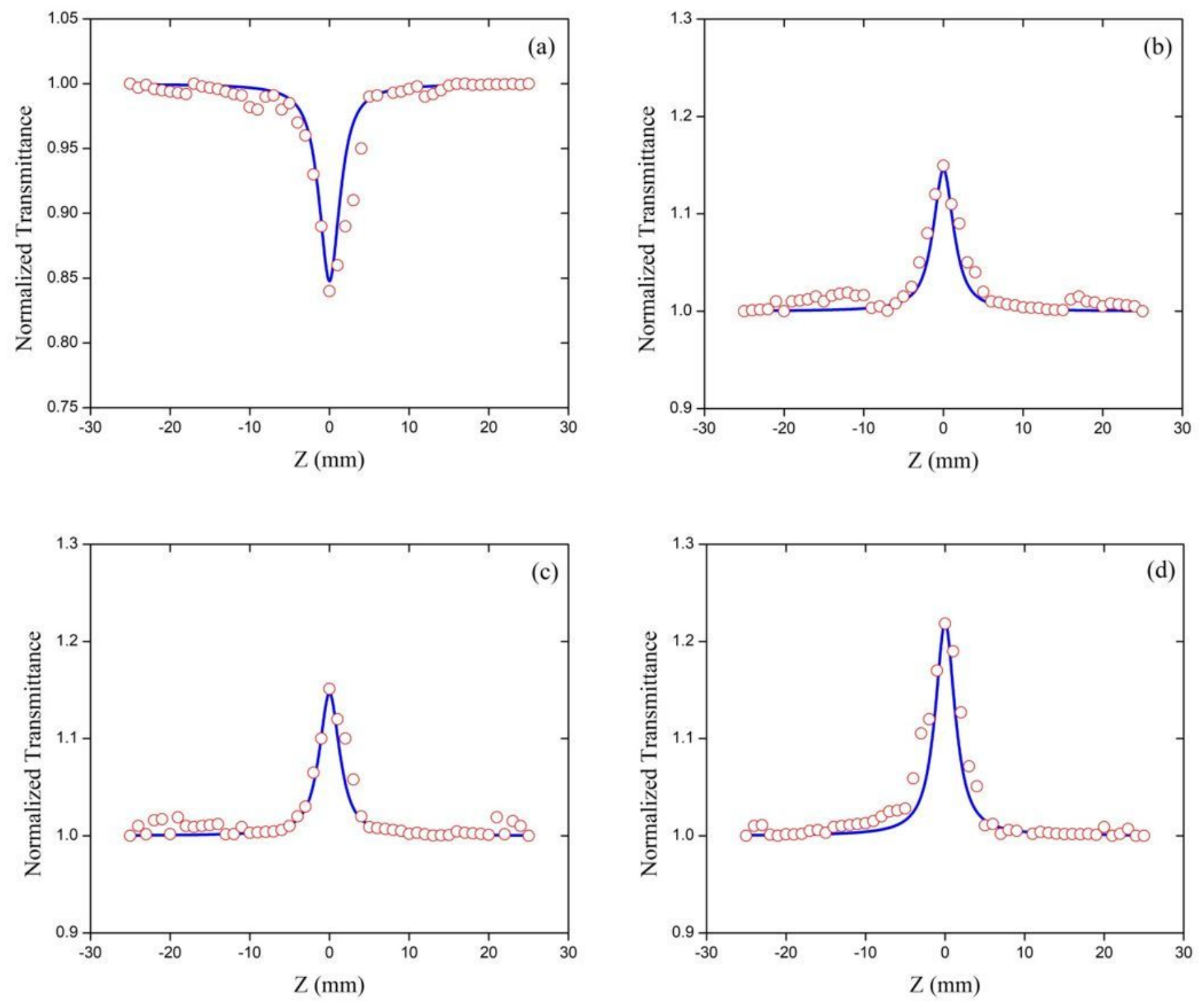

Figure 4

Open aperture Z\scan curve of basic violet 3 dye dissolved in (a) Ethanol (b) 1-propanal (c) DMSO (d) Acetone. 

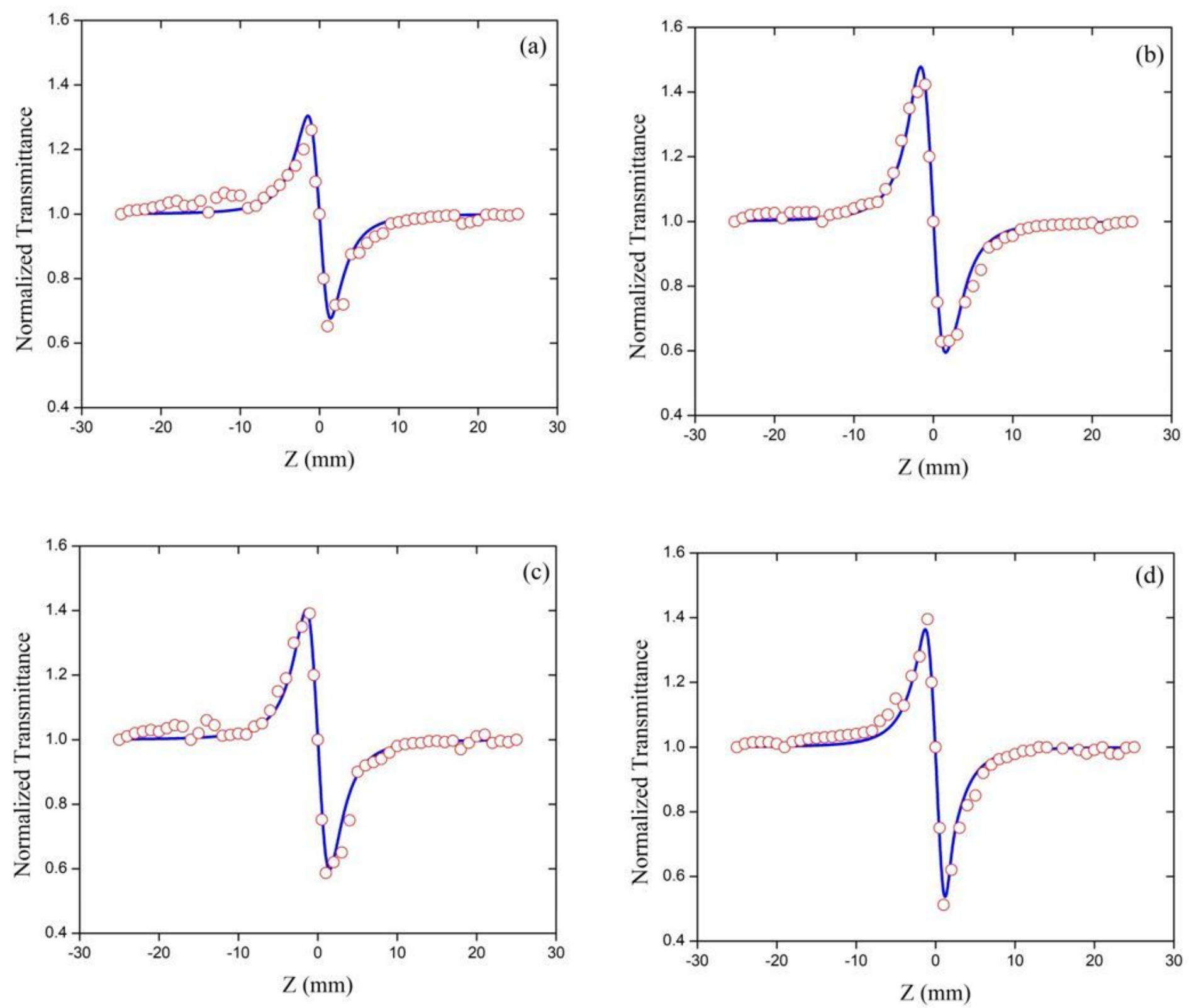

Figure 5

Closed aperture Z\scan curve of basic violet 3 dye dissolved in (a) Ethanol (b) 1-propanal (c) DMSO (d) Acetone. 